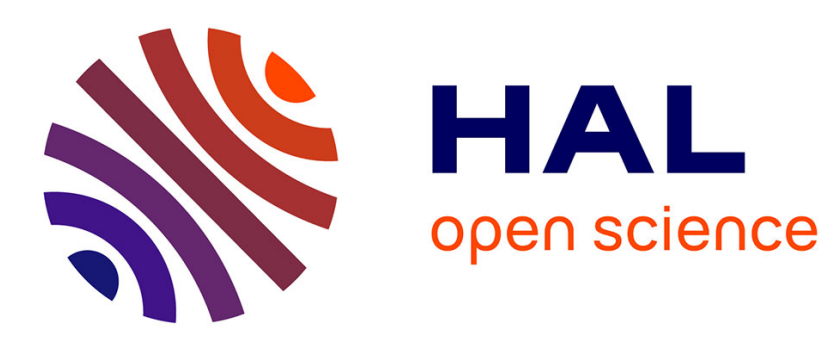

\title{
Generation of parity equations for singular systems. Application to diagnosis
}

Didier Maquin, Besma Gaddouna, José Ragot

\section{To cite this version:}

Didier Maquin, Besma Gaddouna, José Ragot. Generation of parity equations for singular systems. Application to diagnosis. International Conference on Systems, Man and Cybernetics, SMC'93, Jun 1994, Le Touquet, France. pp.400-405, 10.1109/ICSMC.1993.385044 . hal-00201422

\section{HAL Id: hal-00201422 \\ https://hal.science/hal-00201422}

Submitted on 5 May 2014

HAL is a multi-disciplinary open access archive for the deposit and dissemination of scientific research documents, whether they are published or not. The documents may come from teaching and research institutions in France or abroad, or from public or private research centers.
L'archive ouverte pluridisciplinaire HAL, est destinée au dépôt et à la diffusion de documents scientifiques de niveau recherche, publiés ou non, émanant des établissements d'enseignement et de recherche français ou étrangers, des laboratoires publics ou privés. 


\title{
GENERATION OF PARITY EQUATIONS FOR SINGULAR SYSTEMS APPLICATION TO DIAGNOSIS
}

\author{
Didier Maquin, Besma Gaddouna and José Ragot
}

\author{
Centre de Recherche en Automatique de Nancy \\ BP 40 - Rue du doyen Marcel Roubault \\ 54501 Vandoeuvre les Nancy Cedex - FRANCE \\ Phone : (33) $83503080 \quad$ Fax : (33) 83503096
}

\begin{abstract}
In this paper, we show how the generation of parity equations technique can be extended to a singular system. The decomposition of a singular system into two subsystems, a slow and a fast subsystems, allows us to generalize the technique used for standard systems. For an observation horizon with finished length, the system output can be particularly expressed in terms of the initial and terminal state and the inputs; then, the elimination of these two particular states provides the desired parity equations which can be used for diagnosis.
\end{abstract}

\section{INTRODUCTION}

The process diagnosis is presently the major task entrusted to calculators that supervise systems. The precocious detection of unexpected problems in functioning may help to avoid inducing the process into a critical functioning zone by modifying the control law. As known, the diagnosis comprises three important steps: the event detection, the prognostic and the logic decision.

The event detection consists in determining, at any time, the process state of functioning be it normal or abnormal and to detect its evolution. Some of the detected events are normal because they are the result of actions taken by the control system and/or by the operator; the others result from control system or process failure. Therefore, the detection ought to be completed by a recognition phase which is able to classify and to recognize the real failures. After that, an isolation step is necessary to localize the failures and an estimation procedure allows the failure characteristics to be determined; i.e. the amplitude and the duration of failures. The function of prognostic is to define the probable evolution of failure and its consequences on the process functioning. In some cases, the prognostic cannot be established because of lack of information; so it is necessary to wait for more precise recognition of failure characteristics to make a better prognostic. Finally, the decision constitutes the active part of the diagnosis: in terms of the type of the failures and of their foreseeable consequences, the control law ought to be adapted or reconfigured in order to maintain the process objectives. For some failure types, the control law is not modified and a maintenance of the defective components is done (change of a sensor for example). For a process with technological risk, two modes of intervention are generally used: immediate adaptation of control law to reduce failure effects and repairing of defective components.

To detect anomalies, one approach consists in using a process model to control the process behaviour. In this way, we use the analytical redundancy which connects the process inputs and outputs owing to the model. If this latter is correct (i.e. if it provides a reliable image of process behavior), we can check the appropriateness of measurements carried out on the process with the model; a non-null deviation can be a result of component failure of the physical system, or of actuator and/or sensor failures.

In general, the use of models allows us to generate deviation variables called residuals representing the functioning of the system. A residual can be the deviation between the system output and the output predicted by an observer or a Kalman filter. In normal conditions, the residual is statistically null; in the presence of failures, it takes a value whose amplitude and direction are connected to the characteristics of these failures.

A lot of research has been done on the generation of residuals [1], [2], [3]. The techniques use the direct relationships between the inputs and the outputs of the system (transfer function approach), the error of reconstruction issued from a system output observer (for example a Kalman filter innovation sequence), the sequence generated during the identification of system parameters or the redundancy generated by observing the system on a finished horizon (parity space technique). We are interested in this technique developed initially for static systems [4] then extended to dynamic systems [5], [6]. The generation of parity equations for singular systems has not yet been developed a lot; it is the goal of our contribution.

\section{THE REPRESENTATION OF SINGULAR SYSTEMS}

We consider the class of singular systems described by the following discrete equations:

$$
\begin{aligned}
& \mathrm{Ex}(\mathrm{k}+1)=\mathrm{A} x(\mathrm{k})+\mathrm{B} \mathrm{u}(\mathrm{k}) \\
& \mathrm{y}(\mathrm{k})=\mathrm{C} x(\mathrm{k})
\end{aligned}
$$

where $A$ and $E \in R^{n . n}, B \in R^{n \cdot m}, C \in R$ p.n,$x \in R^{n}$, $\mathrm{u} \in \mathrm{R}^{\mathrm{m}}$ and $\mathrm{y} \in \mathrm{R}^{\mathrm{p}}$ 
As it is well-known [7], [8], for any two matrices $\mathrm{E}$ and $\mathrm{A}$ of the same dimensions, there always exist two non-singular matrices $\mathrm{P}$ and $\mathrm{Q}$ such that:

$$
\begin{aligned}
& \text { Q E P }=\operatorname{diag}\left(I_{n 1}, N\right) \\
& \text { Q A P }=\operatorname{diag}\left(A_{1}, I_{n 2}\right)
\end{aligned}
$$

where:

$$
\begin{aligned}
& \mathrm{n} 1+\mathrm{n} 2=\mathrm{n} \\
& \mathrm{A}_{1} \in \mathrm{R}^{\mathrm{n} 1 . \mathrm{n} 1}, \mathrm{~N} \in \mathrm{R}^{\mathrm{n} 2 . \mathrm{n} 2}
\end{aligned}
$$

and $\mathrm{N}$ is a nilpotent matrix with an index $\mathrm{h}$ (this property will not be used in the sequel).

With the change of variables:

$$
\mathrm{x}(\mathrm{k})=\mathrm{P}\left(\begin{array}{l}
\mathrm{x}_{1}(\mathrm{k}) \\
\mathrm{x}_{2}(\mathrm{k})
\end{array}\right)
$$

where $\mathrm{x}_{1} \in \mathrm{R}^{\mathrm{n} 1}, \mathrm{x}_{2} \in \mathrm{R}^{\mathrm{n} 2}$, the system (1) can be partitioned under the following form:

$$
\begin{array}{ll}
\mathrm{x}_{1}(\mathrm{k}+1) & =\mathrm{A}_{1} \mathrm{x}_{1}(\mathrm{k})+\mathrm{B}_{1} \mathrm{u}(\mathrm{k}) \\
\mathrm{N} \mathrm{x}_{2}(\mathrm{k}+1) & =\mathrm{x}_{2}(\mathrm{k})+\mathrm{B}_{2} \mathrm{u}(\mathrm{k}) \\
\mathrm{y}(\mathrm{k}) & =\mathrm{C}_{1} \mathrm{x}_{1}(\mathrm{k})+\mathrm{C}_{2} \mathrm{x}_{2}(\mathrm{k})
\end{array}
$$

where $\mathrm{CP}=\left(\begin{array}{ll}\mathrm{C}_{1} & \mathrm{C}_{2}\end{array}\right)$ and $\mathrm{Q} \mathrm{B}=\left(\begin{array}{l}\mathrm{B}_{1} \\ \mathrm{~B}_{2}\end{array}\right)$

This form is said to be the first standard decomposition of a singular system. The subsystem (3a) corresponds to the slow mode and the subsystem (3b) to the fast one. The measurement equation (3c) couples the two subsystems.

Now, we consider the series of values obtained by integrating (1a) between 0 and $\mathrm{L}$. We assume that $\mathrm{L}>\mathrm{n}$. The system states $\mathrm{x}(\mathrm{k})$ are generated from the series $\mathrm{u}(0), \ldots$, $\mathrm{u}(\mathrm{L})$ :

$$
\left(\begin{array}{ccccc}
-\mathrm{A} & \mathrm{E} & \cdot & \cdot & \cdot \\
\cdot & -\mathrm{A} & \mathrm{E} & \cdot & \cdot \\
\cdot & \cdot & \cdot & \cdot & \cdot \\
\cdot & \cdot & -\mathrm{A} & \mathrm{E} & \cdot \\
\cdot & \cdot & \cdot & -\mathrm{A} & \mathrm{E}
\end{array}\right)\left(\begin{array}{c}
\mathrm{x}(0) \\
\mathrm{x}(1) \\
\cdot \\
\cdot \\
\mathrm{x}(\mathrm{L})
\end{array}\right)=\left(\begin{array}{c}
\mathrm{Bu}(0) \\
\cdot \\
\cdot \\
\cdot \\
\mathrm{Bu}(\mathrm{L})
\end{array}\right)
$$

Under the regularity of the system, $\operatorname{Det}(q \mathrm{E}-\mathrm{A}) \neq 0$, Luenberger [9] has shown that a complete solution of the state equation (4) may be obtained whether from $\mathrm{x}(0)$ or from $\mathrm{x}(\mathrm{L})$; moreover, the solution is unique. The equivalent form (3) is well adapted to the search of this solution. Indeed, the equation (3a) is integrated in the forward direction from the initial condition $x_{1}(0)$ and the equation $(3 a)$ is integrated from the terminal condition $\mathrm{x}_{2}(\mathrm{~L})$ in the backward direction:

$$
\begin{aligned}
& \mathrm{x}_{1}(\mathrm{k})=\mathrm{A}_{1}^{\mathrm{k}} \mathrm{x}_{1}(0)+\sum_{\mathrm{i}=0}^{\mathrm{k}-1} \mathrm{~A}_{1}^{\mathrm{k}-\mathrm{i}-1} \mathrm{~B}_{1} \mathrm{u}(\mathrm{i}) \\
& \mathrm{x}_{2}(\mathrm{k})=\mathrm{N}^{\mathrm{L}-\mathrm{k}} \mathrm{x}_{2}(\mathrm{~L})-\sum_{\mathrm{i}=\mathrm{k}+1}^{\mathrm{L}} \mathrm{N}^{\mathrm{i}-\mathrm{k}-1} \mathrm{~B}_{2} \mathrm{u}(\mathrm{i}-1)
\end{aligned}
$$

The pair $\left(\mathrm{x}_{1}(0), \mathrm{x}_{2}(\mathrm{~L})\right)$ forms a complete condition which enables to estimate the state and the output of the system as follows:

$$
\begin{aligned}
\mathrm{x}(\mathrm{k})= & \mathrm{P}\left(\begin{array}{c}
\mathrm{x}_{1}(\mathrm{k}) \\
\mathrm{x}_{2}(\mathrm{k})
\end{array}\right) \\
\mathrm{x}(\mathrm{k})= & \mathrm{PE}_{1}\left(\mathrm{~A}_{1}^{\mathrm{k}} \mathrm{x}_{1}(0)+\sum_{\mathrm{i}=0}^{\mathrm{k}-1} \mathrm{~A}_{1}^{\mathrm{k}-\mathrm{i}-1} \mathrm{~B}_{1} \mathrm{u}(\mathrm{i})\right) \\
& +\mathrm{P} \mathrm{E}_{2}\left(\mathrm{~N}^{\mathrm{L}-\mathrm{k}} \mathrm{x}_{2}(\mathrm{~L})-\sum_{\mathrm{i}=\mathrm{k}+1}^{\mathrm{L}} \mathrm{N}^{\mathrm{i}-\mathrm{k}-1} \mathrm{~B}_{2} \mathrm{u}(\mathrm{i}-1)\right)(6 \mathrm{a}) \\
\mathrm{y}(\mathrm{k})= & \mathrm{C} \mathrm{x}(\mathrm{k}) \\
\text { with } \mathrm{E}_{1} & =\left(\begin{array}{c}
\mathrm{I} \\
0
\end{array}\right) \text { and } \mathrm{E}_{2}=\left(\begin{array}{c}
0 \\
\mathrm{I}
\end{array}\right)
\end{aligned}
$$

This general form provides the state and the output of the system at each moment in function of the input sequence. It presents the particularity to depend on an initial state and a terminal state; moreover, the solution at the moment $\mathrm{k}$ depends not only on the previous inputs but also on the future inputs until the end of the observation horizon L.

\section{PRINCIPLE OF REDUNDANCIES GENERATION}

As previously mentioned, the fundamental idea of residual generation consists in using some existing redundancies between different variables of the system. This redundancy may take two essential forms: the direct redundancy or the hardware redundancy (relation between the sensor outputs at each moment) and the temporal redundancy or analytic redundancy (time-dependant relation between the actuator inputs and the sensor outputs). The use of those relations allows us to compare the system outputs. The residuals obtained from this comparison constitute a measurement of the non-functioning of the process or of its control system.

Let us consider the process described by the state equations (1). The direct redundancy between the sensors will exist if one of the sensor signal can be valued, at each moment, by the other sensor signals. This corresponds to a situation where some rows of the matrix $\mathrm{C}$ are linearly dependant. In this case, we can find a matrix $\Omega$ which satisfies:

$$
\Omega \mathrm{C}=0
$$

This allows the redundancy relation to be written as: 


$$
\Omega \mathrm{y}(\mathrm{k})=0
$$

This relation holds when all sensors are well-functioning. Should it be otherwise, one defines a residual vector $\mathrm{r}(\mathrm{k})$ :

$$
\mathrm{r}(\mathrm{k})=\Omega \mathrm{y}(\mathrm{k})
$$

where the amplitude and the direction characterize the output failure. So, the direct redundancy allows us to detect and to localize (with respect to some isolability conditions) the sensor failures. But it is ineffective to supervise the process actuators. The temporal redundancy connects the input variables and the output variables during the time. Then it allows us to detect the actuator and the sensor failures. The generation of these redundancies may directly be obtained from the process state equations. From the model (1) with square matrices $\mathrm{A}$ and $\mathrm{E}$, the unknown state $\mathrm{x}(\mathrm{k})$ of the system can be easily eliminated:

$$
\mathrm{y}(\mathrm{k})-\mathrm{C}(\mathrm{q} E-\mathrm{A})^{-1} \mathrm{~B} \mathrm{u}(\mathrm{k})=\mathrm{r}(\mathrm{k})
$$

When failures do not occur, the vector $r(k)$ is equal to zero at each moment. It is sensitive to process input and output failures; indeed, by a simple differentiation, we obtain:

$$
\left(\begin{array}{l}
\mathrm{I} \\
-\mathrm{C}(\mathrm{q} \mathrm{E}-\mathrm{A})^{-1} \mathrm{~B}
\end{array}\right)\left(\begin{array}{c}
\Delta \mathrm{y}(\mathrm{k}) \\
\Delta \mathrm{Du}(\mathrm{k})
\end{array}\right)=\Delta \mathrm{r}(\mathrm{k})
$$

This equation connects the amplitudes of the sensor and actuator failures $\Delta \mathrm{y}(\mathrm{k})$ and $\Delta \mathrm{u}(\mathrm{k})$, to the residual one $\Delta \mathrm{r}(\mathrm{k})$. This form allows us to state some simple rules for failure detection and isolation. For failure detection of the $i^{\text {th }}$ actuator to be detectable, the $\mathrm{i}^{\text {th }}$ column of the inverse of the matrix $\mathrm{C}(\mathrm{q} E-\mathrm{A})^{-1} \mathrm{~B}$, might not be null; according to the same principle, we remark that a sensor failure is always detectable. Two failures $i$ and $j$ are isolable if the $i^{\text {th }}$ and the $\mathrm{j}^{\text {th }}$ columns of the matrix in (11) are distinct and different of the other columns. From a practical aim, we note that the vectors we have to test the independence, result from a rational fraction matrix; it may be easier to test this independence from a coprime factorization, using polynomial matrices computed from the system transfer function.

We note that the equation (11) can be developed to express, during the time, the residuals $\Delta \mathrm{r}(\mathrm{k})$ in terms of failures $\Delta \mathrm{u}(\mathrm{k})$ and $\Delta \mathrm{y}(\mathrm{k})$. This form is only available for singular systems with square matrices $\mathrm{A}$ and $\mathrm{E}$; it requires the calculus of the inverse matrix of q E - A. A slightly different formulation can be proposed. First, the state equation is written as:

$$
\begin{aligned}
& (\mathrm{q} E-A) x(k)-B u(k)=0 \\
& y(k)-C x(k)=0
\end{aligned}
$$

or under a compact form:

$$
\left(\begin{array}{ccc}
\mathrm{q} E-\mathrm{A} & -\mathrm{B} & 0 \\
\mathrm{C} & 0 & -\mathrm{I}
\end{array}\right)\left(\begin{array}{l}
\mathrm{x}(\mathrm{k}) \\
\mathrm{u}(\mathrm{k}) \\
\mathrm{y}(\mathrm{k})
\end{array}\right)=\left(\begin{array}{l}
0 \\
0
\end{array}\right)
$$

Let $\omega(q)$ a vector with appropriate size such that:

$$
\omega^{T}(q)\left(\begin{array}{c}
q E-A \\
C
\end{array}\right)=0
$$

The solutions set of (14) constitutes the matrix $\Omega(\mathrm{q})$. The redundancy equations are then obtained by multiplying (13) by $\Omega W$ :

$$
\Omega(q)\left(\begin{array}{cc}
-B & 0 \\
0 & -I
\end{array}\right)\left(\begin{array}{l}
u(k) \\
y(k)
\end{array}\right)=0
$$

Numerically, the only difficulty consists to solve the equation (14) with regard to $\omega$. The solution can be searched under a polynomial form: $\omega(q)=\omega_{0}+q \omega_{1}+\ldots+q^{j} \omega_{j}$. The coefficients $\omega_{j}$ are then solutions of a simple linear system and moreover it is possible to define, a priori, the index value $\mathrm{j}$ [7].

\section{GENERATION OF PARITY EQUATIONS}

Previously, we have established the expression of the state $\mathrm{x}(\mathrm{k})$ and the output $\mathrm{y}(\mathrm{k})$ in terms of the sequence of the inputs $\mathrm{u}(\mathrm{k})$. The obtained solution depends on the initial state $\mathrm{x}_{1}(0)$ and on the terminal state $\mathrm{x}_{2}(\mathrm{~L})$. The elimination of these particular states allows the parity equations to be deduced from this expression. Remember that the aim of the generation of parity equations is to provide equations which only depend on known or measured variables that is the inputs $u(k)$ and the outputs $y(k)$. The principle of the generation is simple: we have just to eliminate, at different moments of observation and from the different expressions of outputs $\mathrm{y}(\mathrm{k})$, the undesirable states $\mathrm{x}_{1}(0)$ et $\mathrm{x}_{2}(\mathrm{~L})$. Let us consider the case where $\mathrm{L}=3$ (generalizing for an horizon with any dimension does not present a particular problem).

We deduce from $(5 a)$ and $(5 b)$ that:

$$
\left(\begin{array}{l}
\mathrm{x}_{1}(0) \\
\mathrm{x}_{2}(0) \\
\mathrm{x}_{1}(1) \\
\mathrm{x}_{2}(1) \\
\mathrm{x}_{1}(2) \\
\mathrm{x}_{2}(2) \\
\mathrm{x}_{1}(3) \\
\mathrm{x}_{2}(3)
\end{array}\right)=\left(\begin{array}{cc}
\mathrm{I} & 0 \\
0 & \mathrm{~N}^{3} \\
\mathrm{~A}_{1} & 0 \\
0 & \mathrm{~N}^{2} \\
\mathrm{~A}_{1}^{2} & 0 \\
0 & \mathrm{~N} \\
\mathrm{~A}_{1}^{3} & 0 \\
0 & \mathrm{I}
\end{array}\right)\left(\begin{array}{l}
\mathrm{x}_{1}(0) \\
\mathrm{x}_{2}(3)
\end{array}\right)
$$




$$
+\left(\begin{array}{ccc}
0 & 0 & 0 \\
-\mathrm{B}_{2} & -\mathrm{NB}_{2} & -\mathrm{N}^{2} \mathrm{~B}_{2} \\
\mathrm{~B}_{1} & 0 & 0 \\
0 & -\mathrm{B}_{2} & -\mathrm{NB}_{2} \\
\mathrm{~A}_{1} \mathrm{~B}_{1} & \mathrm{~B}_{1} & 0 \\
0 & 0 & -\mathrm{B}_{2} \\
\mathrm{~A}_{1}^{2} \mathrm{~B}_{1} & \mathrm{~A}_{1} \mathrm{~B}_{1} & \mathrm{~B}_{1} \\
0 & 0 & 0
\end{array}\right)\left(\begin{array}{l}
\mathrm{u}(0) \\
\mathrm{u}(1) \\
\mathrm{u}(2)
\end{array}\right)
$$

The system output is then defined by:

$$
\begin{aligned}
& \mathrm{Y}=\left(\begin{array}{cccccccc}
\mathrm{C}_{1} & \mathrm{C}_{2} & 0 & 0 & 0 & 0 & 0 & 0 \\
0 & 0 & \mathrm{C}_{1} & \mathrm{C}_{2} & 0 & 0 & 0 & 0 \\
0 & 0 & 0 & 0 & \mathrm{C}_{1} & \mathrm{C}_{2} & 0 & 0 \\
0 & 0 & 0 & 0 & 0 & 0 & \mathrm{C}_{1} & \mathrm{C}_{2}
\end{array}\right) \\
& \mathrm{Y}=\left(\begin{array}{l}
\mathrm{y}(0) \\
\mathrm{y}(1) \\
\mathrm{y}(2) \\
\mathrm{y}(3)
\end{array}\right)=\mathbf{A}\left(\begin{array}{l}
\mathrm{x}_{1}(0) \\
\mathrm{x}_{2}(3)
\end{array}\right)+\mathbf{B}\left(\begin{array}{l}
\mathrm{u}(0) \\
\mathrm{u}(1) \\
\mathrm{u}(2)
\end{array}\right)
\end{aligned}
$$$$
\left(\begin{array}{l}
\mathrm{x}_{1}(0) \\
\mathrm{x}_{2}(0) \\
\mathrm{x}_{1}(1) \\
\mathrm{x}_{2}(1) \\
\mathrm{x}_{1}(2) \\
\mathrm{x}_{2}(2) \\
\mathrm{x}_{1}(3) \\
\mathrm{x}_{2}(3)
\end{array}\right)
$$

with:

$$
\begin{aligned}
\mathbf{A} & =\left(\begin{array}{cc}
\mathrm{C}_{1} & \mathrm{C}_{2} \mathrm{~N}^{3} \\
\mathrm{C}_{1} \mathrm{~A}_{1} & \mathrm{C}_{2} \mathrm{~N}^{2} \\
\mathrm{C}_{1} \mathrm{~A}_{1}^{2} & \mathrm{C}_{2} \mathrm{~N} \\
\mathrm{C}_{1} \mathrm{~A}_{1}^{3} & \mathrm{C}_{2}
\end{array}\right) \\
\mathbf{B} & =\left(\begin{array}{ccc}
-\mathrm{C}_{2} \mathrm{~B}_{2} & -\mathrm{C}_{2} \mathrm{NB}_{2} & -\mathrm{C}_{2} \mathrm{~N}^{2} \mathrm{~B}_{2} \\
\mathrm{C}_{1} \mathrm{~B}_{1} & -\mathrm{C}_{2} \mathrm{~B}_{2} & -\mathrm{C}_{2} \mathrm{NB}_{2} \\
\mathrm{C}_{1} \mathrm{~A}_{1} \mathrm{~B}_{1} & \mathrm{C}_{1} \mathrm{~B}_{1} & -\mathrm{C}_{2} \mathrm{~B}_{2} \\
\mathrm{C}_{1} \mathrm{~A}_{1}^{2} \mathrm{~B}_{1} & \mathrm{C}_{1} \mathrm{~A}_{1} \mathrm{~B}_{1} & \mathrm{C}_{1} \mathrm{~B}_{1}
\end{array}\right)
\end{aligned}
$$

Let us consider the vector $\Omega$ such that $\Omega \mathbf{A}=0$. If this vector exists, we will define the vector $\mathrm{p}(0)$ described by :

$$
\mathrm{p}(0)=\Omega\left(\left(\begin{array}{l}
\mathrm{y}(0) \\
\mathrm{y}(1) \\
\mathrm{y}(2) \\
\mathrm{y}(3)
\end{array}\right)-\mathbf{B}\left(\begin{array}{l}
\mathrm{u}(0) \\
\mathrm{u}(1) \\
\mathrm{u}(2)
\end{array}\right)\right)
$$

The equation (18) is expressed in terms of known variables (system inputs or outputs) and particularly it is independent on the system state $\mathrm{x}(\mathrm{k})$. The existence of the parity vector depends on the $\Omega$ matrix structure. If $\operatorname{rank}(\mathbf{A})<$ number of rows of $\mathbf{A}$, the solution $\Omega$ exists then the parity vector can be defined; increasing the duration of the observation horizon, this condition can always be satisfied. The size of the parity vector depends on the state equations and also on the duration of observation horizon. As in standard system case, it is possible to bound the horizon length by using a consequence of Cayley-Hamilton's theorem. The quantity $\mathrm{p}(\mathrm{k})$ is known as generalized parity vector which is extended here to singular systems case. It depends in amplitude and direction, on different values of system inputs and outputs. It is clear that, under normal circumstances the vector $\mathrm{p}(\mathrm{k})$ is close to zero. When a fault occurs (involving abnormal values in the series $\mathrm{y}(\mathrm{k})$ and/or $\mathrm{u}(\mathrm{k}))$, $\mathrm{p}(\mathrm{k})$ differs significantly from zero.

This technique allows us to generate some parity equations which depend on all process inputs and outputs. Then, generally, each component of the parity vector is sensitive to different sensor and actuator failures.

In practice, an essential quality of supervision and diagnosis system is its aptitude to isolate the failures, i.e. to distinguish failures. For this, it is desirable to structure the parity vector $\mathrm{p}(\mathrm{k})$ for making its components sensitive to failures we want to detect and insensitive to the others.

Let us consider the expression (18) under the form:

$$
\mathrm{p}(0)=\mathrm{M}(\mathrm{y}(0) \mathrm{y}(1) \ldots \mathrm{u}(0) \ldots \mathrm{u}(\mathrm{L}))^{\mathrm{T}}
$$

with $\mathrm{M}=\left(\begin{array}{ll}\Omega & -\Omega \mathrm{B}\end{array}\right)$

In order to point out this isolability ability, we define an occurrence matrix $\mathbf{O}$ by its elements $\mathbf{O}_{\mathrm{ij}}$ :

$$
\begin{aligned}
& \mathbf{O}_{\mathrm{ij}}=1 \text { if } \mathbf{M}_{\mathrm{ij}} \neq 0 \\
& \mathbf{O}_{\mathrm{ij}}=0 \text { if } \mathbf{M}_{\mathrm{ij}}=0
\end{aligned}
$$

In other terms, $\mathbf{M}$ is a matrix representing the relations between the process inputs and outputs; $\mathbf{O}_{\mathrm{ij}}=1$ yields that a failure on the $\mathrm{j}^{\text {th }}$ variable (sensor or actuator) has an influence on the $\mathrm{i}^{\text {th }}$ component of the parity vector and $\mathbf{O}_{\mathrm{ij}}=0$ involves that this variable has not any influence on the others. Analyzing the matrix $\mathbf{O}$, allows us, a priori, to know the failure influences on the components of $\mathrm{p}(\mathrm{k})$. The detection of the failure of the $\mathrm{j}^{\text {th }}$ measurement is ensure if the $\mathrm{j}^{\text {th }}$ column $\mathbf{O}_{. j}$ of $\mathbf{O}$ is not null; the isolation of this failed measurement is theoretically ensure if the column $\mathbf{O}_{. j}$ is different from the others [10]. In practice, we are interested in isolation in a statistical sense, because a failure (for example a sensor bias) is generally mixed with random noise. Then we do not base our reasoning on variable occurrence only; a detection threshold has to be defined in order to decide, if a parity vector component is upper this threshold, that a failure 
occurs [11], [12]. If the isolation cannot be achieved, it is necessary to transform the parity equations to attain this aim. The new parity vector may has the same size as the first one (but the parity equations are then structured differently), a smaller size (if we are interested in the detection of privileged failures) or a bigger one (in this case, supplementary independent or not parity equations have to be generated). In any cases, the construction of other parity vectors requires a modification of the instrumentation system and generally a precise definition of the measurement matrix $\mathrm{C}$ to guarantee the isolation of any failures. In any cases, the restructuration of the parity equations leads to design, in the most interesting manner, the position of " 0 " and " 1 " of the occurrence matrix. In the simple event of the structure of the observation matrix $\mathrm{C}$ is not modified, the problem can be formulated as follows: we dispose of the occurrence matrix $\mathbf{O}$ which corresponds to a structure of the parity equations, we assign the structure of ideal occurrence matrix $\mathbf{O}_{\mathrm{r}}$ (i.e. which satisfies isolability constraints) and we search the transformation which allows us, by linear combination of the primary parity equations, to transform the matrix $\mathbf{O}$ into its ideal form $\mathbf{O}_{\mathrm{r}}$ [2].

The problem of sensor failure isolation can also be more easily solved by generating a parity equation for each sensor. One only has to apply successively the previous technique for each row of the matrix $\mathrm{C}$.

\section{EXAMPLE}

We consider the following system:

$$
\begin{aligned}
& \left(\begin{array}{llll}
1 & 0 & 0 & 0 \\
0 & 1 & 0 & 0 \\
0 & 0 & 0 & 1 \\
0 & 0 & 0 & 0
\end{array}\right) \mathrm{x}(\mathrm{k}+1)=\left(\begin{array}{cccc}
1 & 1 & 0 & 0 \\
0 & 1 & 0 & 0 \\
0 & 0 & 1 & 0 \\
0 & 0 & 0 & 1
\end{array}\right) \mathrm{x}(\mathrm{k})+\left(\begin{array}{cc}
0 & 1 \\
1 & 0 \\
1 & 0 \\
-1 & 0
\end{array}\right) \mathrm{u}(\mathrm{k}) \\
& \mathrm{y}(\mathrm{k})=\left(\begin{array}{llll}
0 & 1 & 1 & 0 \\
1 & 0 & 0 & 0
\end{array}\right) \mathrm{x}(\mathrm{k})
\end{aligned}
$$

Applying the previous technique, we obtain for a horizon $\mathrm{L}=2$ :

$$
\Omega=\left(\begin{array}{cccccc}
1 & 0 & 0 & 1 & 0 & -1 \\
0 & 1 & 0 & -2 & 0 & 1
\end{array}\right) \quad \mathbf{B}=\left(\begin{array}{cccc}
-1 & 0 & 1 & -1 \\
0 & 0 & 0 & 0 \\
1 & 0 & -1 & 0 \\
0 & 1 & 0 & 0 \\
1 & 0 & 1 & 0 \\
1 & 1 & 0 & 1
\end{array}\right)
$$

The parity equations (18) are then be written:

$$
\begin{aligned}
& \mathrm{p}_{1}(0)=\mathrm{y}_{1}(0)+\mathrm{y}_{2}(1)-\mathrm{y}_{2}(2)+2 \mathrm{u}_{1}(0)-\mathrm{u}_{1}(1)+2 \mathrm{u}_{2}(1) \\
& \mathrm{p}_{2}(0)=\mathrm{y}_{2}(0)-2 \mathrm{y}_{2}(1)+\mathrm{y}_{2}(2)-\mathrm{u}_{1}(0)+\mathrm{u}_{2}(0)-\mathrm{u}_{2}(1)
\end{aligned}
$$

These equations may also be expressed in terms of the delay operator q:

$$
\begin{aligned}
& \mathrm{p}_{1}(\mathrm{k})=\mathrm{y}_{1}(\mathrm{k})+\mathrm{q}(1-\mathrm{q}) \mathrm{y}_{2}(\mathrm{k})-(2+\mathrm{q}) \mathrm{u}_{1}(\mathrm{k})+2 \mathrm{qu}_{2}(\mathrm{k}) \\
& \mathrm{p}_{2}(\mathrm{k})=\mathrm{y}_{1}(\mathrm{k})-\mathrm{q}(2-\mathrm{q}) \mathrm{y}_{2}(\mathrm{k})-\mathrm{u}_{1}(\mathrm{k})+(1-\mathrm{q}) \mathrm{u}_{2}(\mathrm{k})
\end{aligned}
$$

Let us remark here that the system order is equal to 4 and that the observation horizon $\mathrm{L}$ has been chosen less or equal to 2. It means that all potential redundancies of the system have not been necessary exploited. However, the components of the parity vector are sensitive to both actuator and sensor faults and therefore the fault detectability is guaranteed.

\section{CONCLUSION}

We have proposed an extension of generating parity equations to singular systems. These equations can be useful in a procedure of detection and isolation of sensor or actuator failures.

\section{REFERENCES}

[1] R. N. Clark. A simplified instrument failure detection scheme. IEEE Trans. Aero. and Electronic System, AES-14 (4), p. 558-563, 1978.

[2] J.J. Gertler. Augmented models for statistical fault isolation in complex dynamic systems. Proceedings of the 1985 IEEE American Control Conference, p. 317 322, Boston, 1985.

[3] J. Ragot, D. Maquin and F. Kratz. Analytical redundancy for systems with unknown inputs. Application to faults detection. Control Theory and Advanced Technology, vol. 9, $\mathrm{n}^{\circ} 3,1993$ (to appear).

[4] D. Potter, M.C. Suman. Thresholdless redundancy management with arrays of skewed instruments. Electronic flight control systems, Agardograph 224, p. 2115-2121, 1977.

[5] M. Labarrère, M. Pircher, S. Trabulsi. Détection de pannes de capteurs par utilisation de la redondance analytique. Rapport de recherche CERT-DRET $n^{\circ} 77$ 408, 1978.

[6] E. Y. Chow and A.S. Willsky. Analytical redundancy and the design of robust failure detection systems. IEEE Trans. on Auto. Control, AC-29 (7), p. 603-614, 1984.

[7] F. R. Gantmacher. The theory of matrices. Chelsea Publishing Company, 1959.

[8] L. Dai. Singular Control Systems. Lecture Notes in Control and Information Sciences. Springer Verlag 1989. 
[9] D. Luenberger. An introduction to observers. IEEE Trans. on Auto. Control, AC-16 (6), 1972.

[10] Y. Ben-Haim. An algorithm for failure location in a complex network. Nuclear Sciences Engineering, Technical note, 75, p. 191-199, 1980

[11] J.J. Gertler. An evidential reasoning extension to quantitative model-based failure diagnosis. IEEE Trans. on Syst. Man and Cybern., SMC-22 (2), p. 275-289, 1992.

[12] J.P. Cassar, M. Staroswiecki, R. Ferhati. Multivalued logic voting scheme for residual evaluation in failure detection and isolation systems. IFAC/IFIP/IMACS Symposium on Artificial Intelligence in Real Time Control, Delft, june 1992. 